\title{
Vilém Flusser e Marshall McLuhan e as eras comunicacionais
}

\section{Rodrigo Miranda Barbosa}

Doutor, Universidade Federal de Pernambuco, Caruaru, PE, Brasil rmbdesign@gmail.com

\section{Resumo}

$\mathrm{O}$ artigo propõe debater sobre como Vilém Flusser e Marshall McLuhan discutem as transições entre diferentes eras comunicacionais. Através de análise bibliográfica concluímos que eles compartilham a centralidade da comunicação para compreender a sociedade, assim como a não neutralidade dos meios de comunicação. Concluímos que Flusser está mais próximo de McLuhan do que ele admite, mas que há importantes diferenças na forma como compreendem as transições entre as eras comunicacionais.

\section{Palavras-chave}

Vilém Flusser. Marshall McLuhan. Epistemologia da Comunicação. Eras comunicacionais.

\section{Introdução}

Individualmente, muito já foi escrito sobre Vilém Flusser e Marshall McLuhan. Vilém Flusser, autodidata nascido na República Tcheca, fugindo do nazismo, encontra refúgio no Brasil e por aqui fica de 1940 até 1972 - quando então se muda para a Europa durante a ditadura brasileira.

Apesar de não ter nenhum diploma formal, por aqui fundou uma das principais faculdades no país (FAAP), lecionou a disciplina de Teorias da Comunicação e é conhecido internacionalmente como um dos mais importantes pensadores da filosofia do design, mas também dos meios de comunicação (em especial fotografia) e da teoria literária.

No Brasil, tem sido recentemente recuperado para além do clássico A Filosofia da Caixa Preta (1985) - no qual discute o aparecimento da fotografia e de outros meios de comunicação e seus efeitos na sociedade - graças ao importante trabalho do Flusser Archive (em Berlim e em São Paulo), que tem apresentado novas facetas do seu pensamento, assim 
como a revista Flusser Studies ${ }^{1}$. As publicações também são numerosas e novas edições foram lançadas bem como livros póstumos editados tanto pela Annablume e pela editora $E$ Realizações. Outro ponto para o aumento da sua visibilidade é a crescente atenção que está sendo projetada sobre as denominadas Teorias Alemãs de Comunicação com a tradução de livros de Friedrich Kittler às quais Flusser muitas vezes é colocado como filiado. Kittler, amigo de Flusser, não por acaso, foi quem o convidou para uma série de palestras em 1991. Kittler também acaba escrevendo posteriormente o prefácio do livro fruto dessas palestras (FELINTO, 2013, p.8).

Tais publicações recentes demonstram a crescente popularidade e retomada dos trabalhos de Flusser, enquanto Marshall McLuhan não teve a mesma sorte, mesmo com seu retorno aos holofotes a partir dos anos 2000.

Marshall McLuhan, professor canadense de Literatura, alcançou seu estrelato na década de 1960, quando suas pesquisas e frases de choque sobre os efeitos dos meios de comunicação extrapolaram as paredes das universidades e foram parar nas ruas e nos meios de comunicação. Suas inúmeras aparições na televisão, rádio, em filme dirigido por Woody Allen e a venda de mais de milhão de cópias do seu livro de bolso $O$ Meio é a Massagem lançado em 1967 (MARCHAND, 1989, p.203) - são marcadores de sua crescente popularidade no período.

Superou o ostracismo na década de 1980 diante das críticas e saturação, sendo recuperado a partir dos anos 2000, quando o debate sobre a Internet, um novo meio de comunicação instigou a sociedade sobre os seus efeitos e seus estudos pareciam se encaixar ainda mais para esta nova era. Ainda assim, apenas o livro Trivium Clássico (2012), McLuhan por McLuhan (2005b) e duas novas impressões de O Meio é a Massagem $(2018,2011)$ foram publicadas de McLuhan no Brasil nos últimos 20 anos.

Ambos foram contemporâneos. Vilém Flusser, falecido em 1991, tinha conhecimento sobre o trabalho realizado por McLuhan a ponto de fazer críticas e de reconhecer sua importância, já Marshall McLuhan, falecido em 1980, não encontramos rastro apontando para o seu conhecimento sobre as abordagens teóricas de Flusser.

Concluir que estes autores compartilham alguns pontos não é pacífico. 0 autor Andreas Ströhl, responsável por uma coletânea de textos de Flusser, afirma que: 
Exceto por raros pontos de contato, seus textos têm menos em comum com os de Marshall McLuhan ou Jean Baudrillard do que com os de Edmund Husserl ou Martin Buber. Flusser permaneceu um estranho, nunca se tornando parte de uma aceita história da filosofia. (STRÖHL, 2002, p. X, tradução nossa) ${ }^{2}$.

Apesar de Ströhl chamar a atenção para o pouco em comum entre os trabalhos de Flusser e McLuhan, outros autores discordam.

No Pósfácio da versão ${ }^{3}$ em inglês de Towards a Philosophy of Photography (2006), o filósofo e historiador da arte Hubertus von Amelunxen diz que o livro é de interesse de qualquer pessoa que esteja preocupada com os efeitos da sociedade da informação, mas mais importante para quem sente falta justamente de Harold Innis e Marshall McLuhan.

Este livro é de interesse primordial para quem está estudando os efeitos da sociedade da informação nas estruturas básicas da existência humana. [...] Estes devem se tornar textos fixos para os leitores de hoje que sentem a falta de um Buckminster Fuller, Harold Innis ou Marshall McLuhan, que sentem que não podem mais cair na Crítica do Julgamento de Kant e que não se sentem totalmente pressionados por Neil Postman (2006, p. 90, tradução nossa) ${ }^{4}$.

A articulação entre os pensamentos de Flusser e McLuhan já foi desenvolvida por alguns autores e autoras. Dentre eles destacamos uma edição especial da revista Flusser Studies, em 2008, dedicada a discutir as relações entre Flusser e McLuhan assim como outros trabalhos como: Kukielko e Rauch (2008), Guasque (2008), Canán (2008), Pandilovski (2016), Mersch (2008), Meulen (2010), Hanke (2012), Schaefer (2011), Weiss (2008). Além disso, em 2012 foi organizado um congresso de dois dias intitulado "Marshall McLuhan and Vilém Flusser" em Winnipeg, no Canadá, com a participação de especialistas e que virou livro (KOHUT, T., PANDILOVSKI, M., 2015).

Nosso desafio aqui é expandir estes trabalhos justamente na discussão sobre como Flusser e McLuhan compreendem a divisão da história a partir de eras comunicacionais e a contribuição para a formação epistemológica da área. Tal debate nos ajuda a esclarecer

\footnotetext{
2 No original: "Except for rare points of contact, his texts have less in common with those of Marshall McLuhan or Jean Baudrillard than with those of Edmund Husserl or Martin Buber. Flusser remained an outsider, never becoming part of an accepted history of philosophy" (STRÖHL, 2002, p. X).

3 Denomino "versão", pois Flusser é conhecido por reescrever ao traduzir seus próprios livros.

4 No original: This book is of prime interest to anyone studying the effects of the information society on the basic structures of human existence.[...] These should become set texts for readers today who feel the lack of a Buckminster Fuller, Harold Innis or Marshall McLuhan, who feel they can no longer fall back on Kant's Critique of Judgement and who do not feel fully stretched by Neil Postman. (2006, p. 90)
} 
estes pontos de divergência e de convergência entre o trabalho desenvolvido por Marshall McLuhan e Vilém Flusser. Para além de ambos se dedicarem à análise dos meios de comunicação, nossa hipótese da relação estreita entre eles dá-se em dois pontos de contato: a) a não neutralidade dos meios e b) a interpretação da história a partir de diferentes eras comunicacionais.

\section{McLuhan e Flusser: a articulação}

Rafael Cardoso (2013) afirma que os estudos de Flusser concentraram-se na relação das imagens e artefatos que seriam base para uma filosofia do design e da comunicação visual; mas, mais do que isso, trata-se de situar a relação dos meios (junção de imagem e artefato, na nossa compreensão) como centrais para sociedade. Pois, é “[...] um pensador único, capaz de situar imagem e artefato em seu devido lugar, no centro nervoso da existência contemporânea" (CARDOSO, 2013, p.10).

A centralidade dos meios de comunicação em Flusser está relacionada com a sua compreensão da Comunicação. Ele desenvolve a comunicação como um elemento central a partir da ideia de que a comunicação é necessária como forma de tornar aceitável a nossa condição de seres humanos (GULDIN, 2008). Comunicamos para:

[...] criar com os outros uma razão para viver. [...] No modelo flusseriano, a questão é diversa: como conseguimos criar, armazenar e distribuir informação com o objetivo de tornar aceitável nossa condição de seres humanos? (GULDIN, 2008, p. 79).

Para Flusser, na luta contra a entropia natural, os seres humanos, para além de adquirir conhecimento, passaram a registrar seus conhecimentos em matéria e a disseminar esse conhecimento (PANDILOVSKI, 2016). Isso muda completamente nossa relação com a expansão do conhecimento. A entropia é justamente o esquecimento natural, por isso qualquer tipo de artefato que produza e armazene informação é considerado como artificial por Flusser.

O caráter artificial da comunicação humana (o fato de que o homem se comunica com outros homens por meio de artifícios) nem sempre é totalmente consciente. Após aprendermos um código, tendemos a esquecer a sua artificialidade: depois que se aprende o código dos gestos, 
pode-se esquecer que o anuir com a cabeça significa apenas aquele "sim" que se serve desse código. (FLUSSER, 2013, p. 90).

A segunda característica é "[...] uma tentativa de negar a morte por meio de acúmulo de informações" (GULDIN, 2008, p.83). 0 terceiro elemento, segundo Guldin (2008, p. 81), da elaboração teórica de Flusser sobre a comunicação é que a teoria da comunicação pertence às humanidades e não às ciências naturais. Isso fortalece o caráter dialógico e intersubjetivo (relação entre as pessoas e pessoas e objetos) da comunicação para Flusser.

0 processo de comunicação é formado por dois princípios que devem estar em equilíbrio: discurso e diálogo (apesar de Flusser favorecer este último). 0 diálogo está relacionado à produção de informação nova a partir da interação e síntese de memórias prévias, enquanto o discurso está mais preocupado com o armazenamento e transmissão das informações/memórias. Nós compartilhamos essas informações para sobreviver ao efeito da entropia da própria natureza.

Ao analisar então as redes comunicacionais a partir desses conceitos, Flusser percebe um desequilíbrio devido à ação dos meios de comunicação de massa, pois eles enviam mensagens e não recebem, o famoso esquema um para muitos. Isso também significa que o próprio diálogo não é mais o mesmo, pois ganha um outro aspecto ou como explica Ströhl "Diálogos ameaçam assumir a função limitada de sincronização." (2002, p. XVII, tradução nossa) 5 . 0 objetivo de Flusser é fortalecer o diálogo como um projeto de liberdade humana contra a dominação da automatização do esquema aparato-operador.

Os meios e seus códigos, como atravessam e modificam o equilíbrio entre diálogodiscurso, passam a ser seu ponto focal de discussão. Ou seja, a estrutura de comunicação da sociedade é elemento central para compreender a sociedade e o ser humano na filosofia dos meios de comunicação de Flusser.

O mesmo acontece com Marshall McLuhan, que durante décadas dedicou-se à análise da importância dos meios de comunicação na sociedade.

Segundo Tremblay (2012, p. 564), todo o pensamento de McLuhan estava baseado em uma convicção: “[...] os meios de comunicação, que definem o ambiente do homem e da sociedade, perturbam todos os aspectos da vida" (TREMBLAY, 2012, p. 564, tradução nossa) ${ }^{6}$. Sendo assim, qualquer modificação no ambiente comunicacional seria seguida por

\footnotetext{
5 No original: “Dialogues threaten to take on the limited function of synchronization.” (2002, p. XVII).

6 No original: "[...] the media, which define the environment of man and society, disrupt all aspects of life" (TREMBLAY, 2012, p. 564).
} 
uma modificação no ambiente social e nossa dependência dos meios de comunicação enquanto extensões de nossos sentidos explicava essa situação.

Isso coloca os meios de comunicação como elemento central para compreensão da sociedade. Para Harold Innis e Marshall McLuhan, os meios de comunicação funcionam como chave de leitura da realidade. 0 diferencial é que a análise dos meios de comunicação feita por eles por não fica restrita apenas ao comportamento de um único meio no passado, mas contempla uma abordagem dos meios enquanto um sistema mediático.

Nesse sentido, a investigação acerca dos meios ao longo da história serve diretamente à interpretação do presente. 0 foco das suas análises está nas transições entre diferentes meios de comunicação, o que os coloca em uma posição diferente daquela de um historiador de um único meio de comunicação.

Podemos perceber que ambos situam os meios de comunicação como importantes elementos para a sociedade. A diferença entre Flusser e McLuhan está, como expressa Canán (2008), no fato de que "McLuhan tende a enfatizar a mídia em geral, enquanto Flusser enfatiza especificamente os códigos de comunicação" (CANÁN, 2008, p. 1, tradução nossa)7. É preciso, então, compreender como Flusser e McLuhan caracterizam os meios de comunicação a partir da não neutralidade dos meios e divisão e interpretação da história a partir de diferentes eras comunicacionais.

\subsection{A interpretação de Flusser}

\section{a) A não neutralidade dos meios}

Para Flusser, os próprios meios de comunicação não são simplesmente suportes para o conteúdo, eles possuem um programa neles mesmos. Como afirma Cardoso (2013, p. 11), “[...] suas análises tendem a se ocupar mais da identificação de estruturas de pensamento do que de sua recepção em determinado meio ou contexto".

0 foco, dessa maneira, não está na recepção, mas na estrutura dos meios e do pensamento que estes meios favorecem. "Não é exagero dizer que conhecemos e vivenciamos o mundo, e que atuamos nele, dentro das estruturas que nos são impostas pelos códigos que nos informam" (FLUSSER, 2002, p. 16, tradução nossa) ${ }^{8}$.

\footnotetext{
7 No original: "McLuhan tends to stress media in general, whereas Flusser specifically stresses the codes of communication" (CANÁN, 2008, p. 1).

${ }^{8}$ No original: "It is no exaggeration to say that we know and experience the world, and that we act in it, within the structures that are imposed on us by the codes that inform us" (FLUSSER, 2002, p. 16).
} 
Em outro livro, denominado Kommunikologie (2007), ele reforça essa potencialidade dos códigos, demonstrando que estes não podem ser considerados neutros.

[...] a importância do código para a cultura não deve ser subestimado. Cada código não dá ao mundo somente um significado específico (codifica o mundo à sua maneira), mas a estrutura dos códigos, organiza igualmente o pensamento, as sensações e vontades (FLUSSER, 2007, p. 242 apud HEILMAIR, 2012, p. 34).

Os códigos são sistemas simbólicos e fenômenos capazes de tomar o lugar dos fenômenos e dar outro sentido para estes. É por isso que o livro de Flusser, Filosofia da caixa preta (1985), não é apenas um livro sobre fotografia como muitos consideraram. A fotografia é apenas um modelo para falar das relações dos meios de comunicação e sociedade. Os meios são analisados por Flusser como aparatos não neutros e que afetam diretamente a experiência de quem interage com eles.

\section{b) A interpretação da história a partir de diferentes eras comunicacionais.}

Flusser divide a história em períodos que são denominados pré-história, história e pós-história e estão diretamente ligados ao que alguns autores denominam de escalada de abstração. Os três períodos estão relacionados ao tipo de imagem e código dominante. No primeiro período, a imagem tradicional, seguida pela escrita e então a imagem técnica. Flusser analisa a estrutura da mensagem como a estrutura do meio, ou "propriedades físicas dos símbolos" (FLUSSER, 2002, p. 15, tradução nossa)9.

\section{Pré-história - imagem tradicional}

Durante a pré-história desenvolvemos as imagens, "imagens são superfícies que pretendem representar algo. [...] são, portanto, resultado do esforço de se abstrair duas das quatro dimensões espácio-temporais, para que se conservem apenas as dimensões do plano" (FLUSSER, 1985, p. 7).

A representação nas pinturas de Lascaux é a transformação das quatro dimensões em duas $^{10}$. Essa capacidade de transformar e decifrar as imagens é denominada imaginação. Para decifrar a imagem é necessário vaguear pela imagem, ou scanning como denomina

\footnotetext{
${ }^{9}$ No original: "physical properties of symbols".

${ }^{10}$ A realidade entendida como feita de 4 dimensões, sendo a quarta dimensão a do tempo.
} 
Flusser. De um lado, a intenção do autor da imagem e de outro o que o receptor cria com base no que está exposto, isso produz uma síntese.

Essa forma de decifrar a imagem é circular segundo Flusser, pois você acaba voltando para pontos das imagens a fim de interpretar. "O olhar diacroniza a sincronicidade imaginística por ciclos" (FLUSSER, 1985, p. 7, grifo do autor). 0 tempo desse olhar para as imagens é circular, e é considerado por Flusser como mítico, mágico, pois não há marcações claras da história.

As imagens serviam para orientar o homem no mundo, mas quando as imagens extrapolam as suas funções elas deixam de orientar. 0 uso das imagens em larga escala desencadeia como consequência a idolatria; elas bloqueiam o acesso a realidade.

\section{História - escrita}

Para lidar com a idolatria surge a escrita. A função da escrita é criticar as imagens e decompô-las. A escrita rasga a imagem e revela o que está por trás dela, a realidade. Realidade que estava ocultada pela idolatria das imagens. Até então o homem vivia no tempo circular, do eterno retorno, em um tempo mágico-mítico. A escrita linear, ordenada com o silabário um atrás do outro cria uma percepção de progresso linear. Uma percepção que acaba com a noção cíclica do tempo, "a escrita é inseparável da 'consciência histórica', o que seria perceptível já desde a sua forma, alinhada e contínua, ou seja, vindo de um passado e apontando para um futuro, e quebrando, assim, a visão cíclica do tempo" (NODARI, 2010, p. 2).

0 que é inaugurado é um modo de pensar histórico criador da percepção do mundo como processo.

\footnotetext{
Em minha terminologia, digo que, antes da invenção da escrita, as pessoas pensavam numa forma "pré-histórica". E depois da invenção do alfabeto, a consciência histórica foi elaborada. Agora, estamos em processo de elaborar um modo de pensar pós-histórico, estrutural. (FLUSSER, 1988).
}

É o que Flusser denomina de pensamento tipificante. "Logo, que a escrita é um gesto de abstração e tipificação. Gutenberg descobriu o que os inventores do alfabeto haviam inventado inconscientemente: o pensamento abstratizante e tipificante" (FLUSSER, 2017, p.124). 
O texto passa a tomar uma importância maior que a imagem tradicional. E o próprio texto também corre o risco de bloquear o acesso à realidade. É o que Flusser vem a denominar de textolatria.

\section{Pós-história - imagem técnica}

Como equilibrar as consequências da textolatria? Uma nova etapa na escala da abstração. Temos aqui o tema principal do livro Filosofia da Caixa Preta (1985): a criação das imagens técnicas a partir da criação da câmara escura, a câmera fotográfica. A câmera fotográfica é resultado, segundo Flusser, do conhecimento científico, que é fruto do conhecimento da escrita/texto. E a imagem que ela produz é uma imagem técnica, é a “imagem produzida por aparelho" (FLUSSER, 1985, p. 24).

A imagem técnica não surge da realidade, das imagens, mas surge a partir dos textos. Da unidimensionalidade do texto e partimos para o abismo da zero-dimensionalidade.

O derradeiro passo da referida 'escada da abstração' se dá com o advento das imagens técnicas ou tecno-imagens, como a fotografia e as demais imagens produzidas por aparelhos (nem ferramentas, nem máquinas). Trata-se então de representações nulodimensionais, números, fórmulas, pontos, retículas, granulações e algoritmos. [...] (BAITELLO, 2004, p. 22).

Flusser, então, explica as relações das imagens técnicas a partir da: máquina fotográfica, da função do fotógrafo, de como enxergamos as fotografias.

\section{Máquina fotográfica}

A câmera fotográfica produz de forma automática as imagens. Na Filosofia da Caixa Preta (1985), Flusser utiliza a linguagem e as metáforas da era da cibernética para compreender meios de comunicação mais antigos. É o caso da câmera fotográfica que atua como uma caixa preta, apenas conhecemos o input (entrada) e o output (saída), mas não sabemos o que acontece no meio do processo.

E o que é essa ideia de black box? É a noção de que você tem um sistema e que você conhece só o input e o output, ou seja, você faz alguma coisa e do outro lado vem um resultado. Você não precisa conhecer dentro da black box como ela funciona para que ela possa operar. (FELINTO, 2013, p. 4). 
O aparato construído possui um programa, sua maneira de enxergar e capturar uma realidade. A essa programação não temos acesso por ser uma caixa preta e ela não pode ser modificada por não compreendemos nada além de seu input e output. Então, como o fotógrafo se comporta diante dessas limitações?

\section{A função do fotógrafo}

0 fotógrafo, enquanto operador da câmera fotográfica, corre o sério risco de ser absorvido pelo programa da câmera e se tornar um funcionário dela, pois desconhece o seu funcionamento.

O fotógrafo operaria apenas no input. Agindo dessa maneira, as imagens técnicas produzidas não são nada mais do que simples produções já programadas no interior da máquina. Com reafirma Arlindo Machado “[...] o funcionário acredita estar criando e exercendo uma certa liberdade, mas a sua escolha será sempre programada, porque é limitada pelo número de categorias inscritas no aparelho ou máquina" (1997, p.3)

Para subverter essa situação, segundo Flusser, o fotógrafo deve brincar com a câmera se quiser se manter como elemento criativo do processo. É a única maneira de criação contra a programação da máquina a fim de criar algo original. Para Flusser (1985, p.41, grifo do autor), "liberdade é jogar contra o aparelho.". As fotografias "melhores" seriam aquelas que evidenciam a vitória da intenção do fotógrafo sobre o aparelho: a vitória do homem sobre o aparelho (FLUSSER, 1985, p. 24).

Essa vitória é expandir os limites da máquina, produzir algo não previsto em sua programação.

\section{Como enxergamos as fotografias}

A fotografia "faz com que o seu observador as olhe como se fossem janelas e não imagens" (FLUSSER, 1985, p. 10). Não percebemos que ela é uma mediação/transformação da realidade. Reagimos às imagens técnicas, na maior parte do tempo, de forma míticomágica. Segundo Flusser, elas “[...] são dificilmente decifráveis pela razão curiosa de que aparentemente não necessitam de ser decifradas" (FLUSSER, 1985, p. 10).

Acreditar que as imagens técnicas são objetivas e excluir a ação do fotógrafo é um erro, mas o oposto disso, que seria acreditar que as imagens técnicas também são totalmente subjetivas é um erro, pois desconsidera-se o programa da máquina enquanto agente ativo. 
O desenvolvimento da imagem técnica inaugura o período da pós-história para Flusser. As imagens técnicas acabam congelando os eventos em cenas e com isso eles não estão mais ligados ao progresso linear típico da história.

\begin{abstract}
Imagens técnicas congelam eventos em cenas. Portanto, a fotografia conta como a primeira imagem pós-histórica, especialmente por causa de suas origens no pensamento formal, calculado e a-histórico. [...] As fotografias são pós-históricas porque não encontram sua origem em um processo de abstração, mas passam por um processo de concretização. Elas foram estudadas falsamente em termos de técnicas de representação. Na verdade, sua estrutura é de projeção (STRÖHL, 2002, p. XXV, tradução nossa) ${ }^{11}$.
\end{abstract}

As imagens técnicas são baseadas na escrita científica. A câmera fotográfica não registra como um espelho a realidade, ao contrário, uma série de teorias científicas estão por trás dessa transcodificação, “[...] são conceitos transcodificados em cenas.” (FLUSSER, 1985, p. 19).Concluímos neste tópico que Vilém Flusser estabelece uma abordagem filosófica dos meios de comunicação. A comunicação enquanto processo é percebida a partir de uma relação existencial, de sobrevivência e de liberdade. Para Flusser, os meios de comunicação desestabilizam o equilíbrio entre o diálogo e o discurso e são atores ativos no processo de comunicação. Seus códigos em conjunto com os programas inseridos nos meios modificam a experiência do uso e estabelecem uma forma de consciência que ultrapassa a esfera do conteúdo afirmando a não neutralidade dos aparatos. Como uma forma de interpretar a história, a partir da divisão em eras comunicacionais, os meios são analisados pela perspectiva dos códigos dominantes em cada era como a imagem tradicional, escrita e imagem técnica

\title{
2.2 McLuhan
}

Seja através dos códigos, seja a partir da experiência dos meios de comunicação, McLuhan coloca os meios de comunicação como ponto central das suas compreensões da sociedade.

\footnotetext{
11 No original: Technical images freeze events into scenes. Therefore, the photograph counts as the first posthistorical image, especially because of its origins in formal, calculated, unhistorical thought. [...] Photographs are posthistorical because they do not find their origin in a process of abstraction, but go through a process of concretization. They have been studied fals ely in terms of techniques of representation. In fact, their structure is one of projection (STRÖHL, 2002, p. XXV).
} 


\section{a) A não neutralidade dos meios}

Para McLuhan, os efeitos das tecnologias - e em especial o dos meios de comunicação baseada nas suas características - foram negligenciados por uma grande parcela dos pesquisadores, pois estes se concentraram no aspecto do conteúdo. Isso é muito importante como ponto de partida, pois eles estão do mesmo lado no sentido de fugirem da noção de que são apenas os usos que determinam a sociedade. Tanto McLuhan quanto Flusser entendem que as tecnologias não são neutras.

É isto que nos permite entender a proposta de McLuhan com a sua expressão: o meio é a mensagem. Independentemente do conteúdo das mensagens, os meios em si têm características que afetam as nossas percepções e alteram o ambiente em que vivemos, essa seria a "mensagem" do meio de comunicação. Ela se refere à potencialidade dos meios de comunicação mudarem como nos comunicamos e com isso alterarem todo o ambiente social.

Para McLuhan, “a 'mensagem' de qualquer meio ou tecnologia é a mudança de escala, cadência ou padrão que esse meio ou tecnologia introduz nas coisas, humanas". (1969, p. 22), algo que para ele havia sido esquecido pelos pesquisadores e que era mais profundo que os efeitos do conteúdo. "As sociedades sempre foram moldadas mais pela natureza da mídia pela qual os homens se comunicam do que pelo conteúdo da comunicação" (McLUHAN, 1967, p.8, tradução nossa).12.

Com essa proposta, McLuhan cria a distinção entre forma e conteúdo preocupando-se com o sistema mediático que compõe o suporte material, o uso da tecnologia como a dificuldade de aprendizagem do código, sua gramática, a capacidade de disseminação no tempo ou no espaço, os sentidos sensoriais requisitados, os serviços e desserviços gerados pela inserção dos meios entre outros, uma preocupação derivada da questão da tecnologia.

Os serviços e desserviços decorrentes da inserção de um novo meio costumam ser invisíveis e imperceptíveis. A explicação de McLuhan para a invisibilidade dos meios de comunicação é de que prestamos atenção apenas no conteúdo das mensagens, não notamos os efeitos dos meios de comunicação no plano da percepção individual, tampouco atentamos para o ambiente da sociedade como um todo. Conforme o meio passa a fazer parte do dia a dia da sociedade e sua penetração é aprofundada, fica mais difícil perceber o ambiente. Mas, de outra parte, é graças à introdução de um novo meio de comunicação que se torna possível

12 No original: "Societies have always been shaped more by the nature of the media by which men communicate than by the content of the communication" (McLUHAN, 1967, p.8) 
perceber o ambiente anterior no qual vivíamos. A inserção de um novo meio de comunicação faz com que os padrões de relações pessoais se modifiquem e novas relações sejam criadas.

Por causa desse tipo de análise, McLuhan foi acusado de ser um determinista tecnológico ao não focar no conteúdo dos meios, mas na forma como estes meios organizam a experiência e a nossa consciência.

\section{b) A interpretação da história a partir de diferentes eras comunicacionais.}

McLuhan desenvolve sua análise dos efeitos dos meios ao periodizar a história a partir dos meios de comunicação e suas características. Para entender essa divisão é preciso compreender primeiro como ele estabelece as características e efeitos dos meios de comunicação. Em seguida, discutimos em específico as transições que o autor estabelece entre a era da oralidade, da imprensa e dos meios de comunicação elétricos.

Explicar a sociedade a partir das eras comunicacionais marca uma importante chave de leitura para estabelecer o que faz com que uma perspectiva teórica possa ser considerada como especificamente comunicacional. Os dois começam a partir das transições desde a oralidade. "Assim, tanto o pensamento de McLuhan quanto o de Flusser começam com a transição das histórias orais para a lógica inerente do alfabeto e sua subsequente moldagem dos processos de pensamento humano." (PANDILOVSKI, 2016, tradução nossa) ${ }^{13}$.

McLuhan tentou várias formas de distinção dos meios, a exemplo de meios quentes e meios frios e, notadamente, entre espaço acústico e espaço visual. Ele selecionou as alterações no sensório humano como forma de compreender as consequências da inserção de novos meios de comunicação, e percebeu dois modos gerais de experiência do ambiente baseadas nos sentidos: o espaço acústico e o espaço visual.

McLuhan, por intermédio do conceito de espaço acústico, chamou a atenção para a possibilidade de outras formas de espaço para além do espaço visual. 0 autor então combinou um modelo de estudo sobre o espaço com um modelo sensorial através da noção de que os meios de comunicação eram extensões espaciais (ambientais) dos nossos sentidos. Sendo assim, a introdução de um novo meio de comunicação reconfigura o sensório humano e como consequência o ambiente (espaço) social com a sua estrutura e as instituições da sociedade.

13 No original: “Thus, both McLuhan's and Flusser's thinking starts with the transitioning from oral histories towards the inherent logic of the alphabet and its subsequent molding of human thought processes." (PANDILOVSKI, 2016). 
Geralmente, quando discutimos o conceito de espaço nos referimos aos modelos de espaço visual, como um espaço que separa os objetos visuais. 0 espaço visual é caracterizado por uma ênfase no sentido da visão. Para McLuhan (1969), a tradução de todos os sentidos para o sentido visual só foi possível com a abstração do alfabeto fonético. A escrita se tornou o meio de comunicação dominante e com isso o espaço visual reinou durante um longo período.

O espaço acústico é a ideia de que o som cria um espaço, um espaço que difere das características do espaço visual. E é considerado como não possuindo um centro, nem margens e não possuindo um centro de direção. 0 espaço acústico é dinâmico, ligado à oralidade, independente das qualidades estáticas, geralmente associadas ao visual (CAVELL, 2005).

A ação dos meios enquanto ligados diretamente aos nossos sentidos provocam mudanças na nossa percepção do espaço. Assim, McLuhan se colocou na posição de estudar como através das tecnologias de comunicação a sociedade produz e modifica de forma dinâmica o ambiente (espaço) e sua concepção sobre o espaço, seja na direção do espaço acústico ou espaço visual.

A concepção de McLuhan (1969) é que os sentidos são interdependentes. Isso significa que qualquer sentido que seja mais requisitado faz diminuir a capacidade dos demais sentidos. Com essa alteração, mudam também as formas pelas quais organizamos a experiência.

Determinados meios vão favorecer uma nova forma de organizar essa experiência e estrutura de percepção. Essa noção faz McLuhan analisar as diferenças estruturais que as transições entre os meios de comunicação causam na sociedade. No caso de McLuhan, há uma transição entre a era da oralidade para a era da escrita e prensa de Gutenberg e por último a era dos meios elétricos.

\section{Oralidade}

É importante frisar que não significa que existia apenas um único meio de comunicação, mas que a forma da experiência era dominada por uma forma específica de interpretar o mundo.

McLuhan (1969) começou a desenvolver a ideia de que a partir do alfabeto fonético houve uma mudança estrutural nas relações humanas em comparação com a oralidade. A oralidade está ligada ao espaço acústico e em uma relação na qual todos os sentidos 
estariam envolvidos, tal como em uma discussão presencial entre duas pessoas na qual os gestos, cheiros, ambiente, audição e visão estão presentes simultaneamente na situação. A consciência está baseada no conhecimento mítico, acústico e de interdependência das pessoas que vivem em conjunto.

\title{
Alfabeto fonético
}

A primeira transição acontece quando são desenvolvidas as primeiras formas de escrita. 0 destaque é dado para o alfabeto fonético, no qual, para McLuhan, há uma ruptura e mudança de percepção.

O alfabeto fonético é diferente dos outros alfabetos até então. Isso acontece, ainda no entendimento de McLuhan (1972), porque ele é o único capaz de separar os sentidos ao favorecer apenas o espaço visual. 0 alfabeto fonético é abstrato ao traduzir sons em uma forma abstrata e diferente das formas dos ideogramas, por exemplo, não tem qualquer relação com as coisas do mundo. Essas alterações entre os espaços são fruto direto da ação dos meios de comunicação.

\begin{abstract}
A invenção do alfabeto, à semelhança da invenção da roda, foi a primeira tradução ou redução de um complexo e orgânico intercâmbio de espaços num único espaço. 0 alfabeto fonético reduziu o uso simultâneo de todos os sentidos, que é a expressão oral, a um simples código visual. [...]. Mas cada uma dessas formas de espaço tem propriedades particulares e incide sobre nossos outros sentidos ou espaços de modo também particular. (McLUHAN, 1972, p. 76).
\end{abstract}

A consequência da inserção do alfabeto fonético em larga escala causa a linearidade do pensamento, individualismo e o racionalismo. Em sociedades letradas o conhecimento é processado de forma linear sequencial, um item de cada vez, conforme a mesma estrutura da palavra escrita. Sendo assim, o espaço visual ganha mais importância que o espaço acústico e o ver para crer começa a se estabelecer.

o impresso impõe a seus utilizadores uma lógica particular de organizar o conhecimento em termos de relações uniformes, lineares, harmoniosas e causais. Essa forma de pensar é extrapolada para outras atividades da sociedade.

$\mathrm{Na}$ oralidade as pessoas compartilham o conhecimento de forma presencial no mesmo espaço/tempo, mas com a escrita é possível um distanciamento. As pessoas são capazes de ler em silêncio e ter um conhecimento diferente de outras pessoas que não tiveram acesso 
ao mesmo material. A mudança entre o espaço acústico para o espaço visual, é crucial para uma nova forma de consciência e McLuhan (1969) investiga um novo processo de transição para os meios de comunicação elétricos e com ela uma nova organização estético-sensorial e mudanças sociais.

\section{Meios elétricos}

McLuhan (1969) percebia também que esse domínio visual baseado na escrita e no impresso estava cedendo lugar aos meios eletrônicos, que iniciaram com o telégrafo, depois o rádio e em seguida a televisão. Surgia a primeira geração que nasceu tendo a televisão como o principal meio de comunicação e, como visto até aqui, a inserção de um novo meio deveria trazer toda uma nova forma de organizar a experiência. Agora a sociedade baseada nos meios elétricos passa por uma nova revolução sensorial que, segundo McLuhan, quebra a linearidade sequencial da cultura baseada no espaço visual desenvolvida principalmente pela escrita e prensa.

0 resultado é a volta da sinestesia. Os meios eletrônicos permitem a todos estarem em contato, o que irá exigir de McLuhan o desenvolvimento de outro conceito importante, o de Aldeia Global. O conceito de Aldeia Global não é um retorno ao bucólico, ao passado harmonioso como muitas pessoas interpretaram, mas que algumas características da oralidade são retomadas na era dos meios elétricos.

Segundo McLuhan, a televisão exige uma participação sensorial envolvente que é tátil, pois a tatilidade é a interrelação entre os sentidos. "Com a televisão, vem a extensão do sentido do tato ou da inter-relação dos sentidos, que envolve mais intimamente ainda todo o nosso mundo sensorial" (1969, p. 298).

Ele acreditava que culturas orais e pré-letradas eram dominadas pelo sentido áudiotátil e que a informação era processada simultaneamente em tempo real. Na era eletrônica, voltaríamos para uma forma de espaço acústico devido à aquisição simultânea da informação, o que nos levaria a recuperar os padrões dos sentidos da era oral.

A abolição do espaço e tempo é um dos efeitos trazidos pelos novos meios. "Uma das peculiaridades da era da eletricidade é que vivemos simultaneamente em todas as culturas do passado. Todo o passado está aqui e todo o futuro está aqui" (McLUHAN, 2003, p. 213, tradução nossa) ${ }^{14}$.

\footnotetext{
${ }^{14}$ No original: "One of the peculiarities of the electric age is that we live simultaneously in all the cultures of the past. All of the past is here and all of the future is here" (McLUHAN, 2003, p. 213).
} 
Como podemos perceber, a transição entre as eras comunicacionais não é uma simples transição entre diferentes meios de comunicação tomados como dominantes, mas o domínio de uma forma de consciência que imputa uma série de consequências no ambiente social uma vez que altera o equilíbrio sensorial e afeta as relações entre as pessoas e a forma como estas organizam o conhecimento.

\section{A articulação entre Flusser e McLuhan}

\section{a) A não neutralidade dos meios}

A não neutralidade dos meios é percebida facilmente em McLuhan através da sua metáfora do "o meio é mensagem" e a noção de caixa preta de Flusser vai no mesmo sentido de McLuhan. Flusser apoia-se na linguagem sobre cibernética de sua época para analisar meios de comunicação do passado. Não só os conceitos de input e output estão presentes na sua discussão sobre a câmera fotográfica como uma caixa preta, mas também o uso da noção de hardware e software. Os códigos seriam justamente o software, o programa da caixa preta e que interfere no processo de comunicação.

Os códigos (e os símbolos que os constituem) tomam-se uma espécie de segunda natureza (FLUSSER, 2013, p. 90)

A propriedade física dos símbolos influencia decisivamente a estrutura dos códigos. É mais influenciado por isso do que pelo critério de significado. A estrutura de uma mensagem reflete o caráter físico de seus símbolos mais do que a estrutura do universo que ela comunica. Isso explica a famosa frase '0 meio é a mensagem'”. (FLUSSER, 2002, p. 15, tradução nossa) ${ }^{15}$.

A forma de Flusser extrapolar o meio e seus códigos (hardware e software) dá-se em afirmações como essa: “[...] a estrutura do texto se imprime nas circunstâncias, assim como a estrutura da imagem. Tanto o texto quanto a imagem são 'mediações'. [...]" (FLUSSER, 2011, p.9, tradução nossa) ${ }^{16}$. Ou seja, a estrutura dos códigos extrapola para a mensagem/texto e para a situação, os meios in-formam, dão forma à circunstância.

\footnotetext{
15 No original: The physical property of symbols influences decisively the structure of the codes. It is influenced more by this than by the criterion of meaning. The structure of a message reflects the physical character of its symbols more than the structure of the universe it communicates. This explains the famous sentence "The medium is the message." (FLUSSER, 2002, p. 15)

${ }^{16}$ No original: "[...] the structure of the text impresses itself on the circumstances, just as the structure of the image did. Both text and image are 'mediations.' [...]" (FLUSSER, 2011, p.9).
} 
Os meios/códigos nos programam para agir e pensar de uma determinada maneira e com isso condicionam o nosso ambiente e a nossa consciência. Muitas vezes sem termos compreensão de que isso está acontecendo.

Quando Flusser (1985) chama a atenção para não sermos funcionários do aparato é justamente pela razão de não compreendermos que os meios e códigos têm esse potencial. McLuhan dedicou boa parte das suas aparições mediáticas a chamar a atenção para a não percepção dos efeitos dos meios de comunicação. Para não sermos funcionários precisamos exercer nossa capacidade de in-formar; capacidade que também está nas estruturas dos códigos. É a única maneira de chegar à liberdade pretendida por Flusser.

Flusser e McLuhan "[...] expôs a visão de que as dimensões de conhecimento e percepções da consciência são modificadas de forma recorrente por meio da adoção de novas formas de intervenção midiática nos atos de comunicação humana." (WEISS, 2008, p.1, tradução nossa) ${ }^{17}$. Ou seja, os meios modificam as percepções da consciência e organização do conhecimento, reforçando o conceito "o meio é a mensagem"; que pode ser percebido como um dos pontos de contato entre Flusser e McLuhan.

\section{b) A interpretação da história a partir de diferentes eras comunicacionais.}

Mais do que uma correspondência entre meios de comunicação ou códigos dominantes, o que estamos estabelecendo são modos de consciência para cada era comunicacional entre Flusser e McLuhan.

Flusser estabelece as eras comunicacionais como pré-história dominada pelo código da imagem tradicional; história como o período dominado pelo código da escrita e por último a pós-história em que há um domínio do código da imagem técnica.

A era da oralidade de McLuhan corresponde à era da imagem tradicional em Flusser. Trata-se de um período mítico, de tempo circular, mágico e da simultaneidade da leitura da imagem. Esse é o modo de consciência tanto da era da oralidade em McLuhan quanto do período da pré-história dominado pela imagem tradicional em Flusser.

\footnotetext{
17 No original: "[...] expounded the view that the knowledge-giving dimensions and perceptions of consciousness are recurrently modified through the adoption of new forms of media intervention to acts of human communication." (WEISS 2008, p.1)
} 
O conceito de eterno retorno ${ }^{18}$ demonstra que a forma de leitura de uma imagem se dá através de um scanning da imagem. A imagem é ambígua e permite múltiplas leituras, isso produz uma sincronicidade dos significados entre a imagem e o receptor.

O vaguear do olhar é circular: tende a voltar para contemplar elementos já vistos. Assim, o "antes" se torna "depois", e o "depois" se torna o "antes". 0 tempo projetado pelo olhar sobre a imagem é o eterno retorno. (FLUSSER, 1985, p. 7).

McLuhan percebe essas características justamente na era da oralidade. A oralidade é dada pela sincronicidade (mesmo tempo e espaço), com todos os sentidos envolvidos. McLuhan também descreve esse período como de vivência mítica, justamente por não ter os sentidos separados em decorrência da invenção da escrita e da racionalidade.

A razão por que achamos difícil compreender os mitos está justamente neste fato: não excluem eles qualquer faceta da experiência como o fazem as culturas alfabetizadas. Todos os níveis de significação são simultâneos. (McLUHAN, 1972, p. 110).

$\mathrm{O}$ alfabeto fonético marca a transição para uma nova era, pois separa a experiência. $\mathrm{Na}$ oralidade todos os sentidos estão envolvidos, mas com o alfabeto fonético há um stress no sentido visual que elimina o envolvimento sensorial de todos os sentidos.

A palavra falada foi traduzida para símbolos visuais abstratos e para sons que também não têm relação uma vez que não se trata de uma imitação de sons da natureza. Por isso McLuhan (1972; 1969) descreve a era da escrita, do espaço visual, como um processo de fragmentação em várias partes.

Tal fragmentação também está na descrição de Flusser ao descrever o desenvolvimento da escrita como uma forma de tradução das imagens tradicionais em escrita.

0 método do rasgamento consistia em desfiar as superfícies das imagens em linhas e alinhar os elementos imaginísticos. Eis como foi inventada a

\footnotetext{
180 conceito de eterno retorno usado por Flusser tem inspiração em Friedrich Nietzsche que o desenvolve como uma forma de escapar no niilismo diante da morte de Deus ao se perguntar se escolheria viver sua vida mais uma vez e outra vez, e assim eternamente. Em Flusser, o conceito aparece posteriormente como repetição e falta de imaginação presentes em uma sociedade do espetáculo das imagens técnicas da pós-história "Isto é o fim da história, porque a rigor nada mais acontece, porque tudo é doravante espetáculo eternamente repetível. A reta da história se transforma no círculo do eterno retorno." (2008, p.99). A materialidade comunicacional torna-se eternamente presente (para seguir a proposta de Nietzsche) e passível de reprodução, dessa forma, fora da linha do tempo.
} 
escrita linear. Tratava-se de transcodificar o tempo circular em linear, traduzir cenas em processos. Surgia assim a consciência histórica, consciência dirigida contra as imagens. (FLUSSER, 1985, p.8).

0 rasgamento consiste em colocar as imagens de forma linear uma depois da outra em linhas, instaurando assim um tipo de mentalidade.

As linhas, portanto, representam o mundo ao projetá-lo em uma série de sucessões. Desse modo, o mundo é representado por linhas, na forma de um processo. 0 pensamento ocidental é "histórico" no sentido de que concebe o mundo em linhas, ou seja, como um processo. (FLUSSER, 2013, p. 103).

Em McLuhan (1969), a escrita é justamente responsável pelo racionalismo, pela fragmentação da experiência e a separação dos sentidos ao favorecer o espaço visual. Para Flusser, a escrita acaba por fazer o "desenrolar da imagem em linhas" (2013, p. 132), ou seja, a imagem que é desenrolada e não a fala, como acontece em McLuhan, na transição da oralidade para a escrita.

Como aponta Canán (2008), um dos elementos que diferencia Flusser e McLuhan no caso da linearidade é que em Flusser a escrita é entendida como o rasgamento da imagem em linhas. Em McLuhan, a escrita é algo completamente novo e essa forma de linearidade estabelecida pela ideia do fonema enquanto abstração e não simplesmente um desenrolar da imagem em linhas. Por isso o alfabeto fonético é diferente de outros códigos escritos como os ideogramas.

Para Flusser, a consequência da escrita é a formação de uma consciência histórica, enquanto em McLuhan apesar de esta característica estar posta o foco está na mecanização, racionalidade, na fragmentação, e no espaço visual. Além disso, Canán (2008) aponta que Flusser foca na questão do tempo circular enquanto McLuhan dirige a sua atenção para a consciência do espaço visual.

Tal transição da imagem tradicional para a escrita (Flusser) e da oralidade para a escrita (McLuhan) estabelecem novas formas de organização da experiência e de consciência. A transição da escrita para a imagem técnica inaugura em Flusser um novo marco que é o da pós-história. Em McLuhan, é a transição da escrita para os meios elétricos que inaugura um novo período da história e uma nova forma de consciência. 
Para Flusser, a imagem técnica é fruto do texto científico, mas ela inaugura uma nova era, que não possui as mesmas características de consciência da escrita. Passamos novamente a viver em um tempo circular e viver miticamente. Inaugura-se assim a póshistória, “[...] estamos nos aproximando de um novo tipo de era mágico-mítico, uma cultura da imagem pós-histórica" (FLUSSER, 2002, p. 66, tradução nossa) ${ }^{19}$.

É o que McLuhan também pensa que seriam os efeitos dos meios de comunicação elétricos. Para ele, teríamos o retorno de várias características da era da oralidade e o total envolvimento das pessoas nos assuntos de todos.

O que difere a explicação de McLuhan para a de Flusser é que não se trata de uma nova tecnologia que traz essa nova era, mas a exaustão da era anterior. Os textos científicos perderam qualquer conexão com a realidade e assim as imagens técnicas "foram inventadas com o objetivo" de devolver significado à vida. Por fim, os elementos que desencadeiam novas eras são pontos de diferenciação das propostas de Flusser e McLuhan.

\section{A contribuição para a Epistemologia da Comunicação}

Flusser tentou estabelecer pontos para a área de Comunicação. Lecionou Teorias da Comunicação, criou o que seria sua Teoria da Comunicação. McLuhan, apesar de metodologicamente querer afirmar que não possuía uma Teoria da Comunicação, cravou o seu nome nos estudos dos meios de comunicação ao chamar a atenção para o aspecto tecnológico.

A centralidade dos meios de comunicação é um dos pontos-chaves que unem os trabalhos de Flusser e McLuhan, apesar das divergências em relação a outros pontos.

Para Canán, ambos poderiam ser considerados como representantes de uma virada midiática. "A teoria midiática historiciza a mente na medida em que é possível chegar a uma explicação histórica da mudança e do desenvolvimento tecnológico, pois essa mudança é de alguma forma espelhada pela estrutura da mente" (2008, p. 1, tradução nossa) ${ }^{20}$.

Ambos compreendem então os meios como atores ativos, não neutros e que favorecem certos tipos de consciência a partir de uma divisão da história a partir de diferentes eras comunicacionais.

\footnotetext{
${ }^{19}$ No original: “[...] we are approaching a new type of magico-mythical age, a post-historical image culture” (FLUSSER, 2002, p. 66).

${ }^{20}$ No original: "Mediatic theory historicizes mind to the extent in which it is possible to reach an historical explanation of technological change and development, for this change is somehow mirrored by the structure of mind" (2008, p. 1).
} 
E que, apesar de algumas divergências (entre quais fatores fazem a transição entre as eras comunicacionais, por exemplo), o que nos interessa nessa aproximação é apontar que eles partem de pontos iniciais em comum para desenvolverem as suas abordagens.

\section{Referências}

BAITELLO JR., Norval. O Leitor Número 69 ou o Marco Zero de um Futuro Flusser. In: FLUSSER, V. Língua e realidade. 2 ed. São Paulo: Annablume, 2004.

CANÁN, A. J. L. C. "McLuhan, Flusser and the Mediatic Approach to Mind". Flusser Studies, [s.l.], n. 6, maio, 2008.

CARDOSO, R. Introdução. In: FLUSSER, V. O mundo codificado. São Paulo: Cosac \& Naif, 2013.

CAVELL, R. "McLuhan and spatial communication". In: GENOSKO, Gary (eds.). Marshall McLuhan: Critical Evaluations in Cultural Theory. Volume II. New York: Routledge, 2005. p. 91-107.

FELinTo, E. Pensamento Poético e Pensamento Calculante: o Dilema da Cibernética e do Humanismo em Vilém Flusser. Flusser Studies, [s.l.], n. 15, maio, 2013.

FLUSSER, V. Da Tipografia. In: Caderno Sesc_Videobrasil 12: metafluxus: 2016/2017. São Paulo: Edições Sesc São Paulo; Videobrasil, 2017. - 166 p. il.

FLUSSER, V.. Filosofia da caixa preta. São Paulo: Hucitec, 1985. 92 p.

FLUSSER, V.. Into the Universe of Technical Image. Minneapolis: Minnesota Press, 2011. FLUSSER, V.. Kommunikologie. Frankfurt/M: Fischer, 2007.

FLUSSER, V.. 0 mundo codificado. São Paulo: Cosac \& Naif, 2013.

FLUSSER, V.. 0 universo das imagens técnicas: elogio da superficialidade. São Paulo: Annablume, 2008.

FLUSSER, V. . "On writing, complexity and the technical revolutions" [Entrevista concedida a Miklós Peternák] Osnabrück, European Media Art Festival, Set. 1988.

FLUSSER, V.. Writings. Org. A. Ströhl. London: Minnesota Press, 2002.

GUASQUE, Y. A cidade como um medium em McLuhan e Flusser. Flusser Studies, [s.l.], n. 6, maio, 2008.

GULDIN, R. Comunicação e Teoria dos Media. In: BERNARDO, G.; FINGER, A.; GULDIN, R. Vilém Flusser: uma introdução. São Paulo: Annablume, 2008. p. 79-105 
HANKE, B. Vilém Flusser's Digital Galaxy. International Journal of Communication 6, Book Review 25-35. 2012.

KUKIELKO, K.; RAUCH, B. Marshall McLuhan \& Vilém Flusser: the new model artists. Flusser Studies, [s.l.], n. 6, may, 2008.

HEILMAIR, A. F. 0 conceito de imagem técnica na comunicologia de Vilém Flusser. Dissertação (Mestrado em Comunicação e Semiótica). São Paulo: PUC-SP, 2012.

KOHUT, T.; PANDILOVSKI, M. Marshall McLuhan and Vilém Flusser's communication and aesthetic theories revisited. Winnipeg: Video Pool Media Arts Centre, 2015.

MACHADO, A. Repensando Flusser e as imagens técnicas. Boletim Flusser, [s.l.], n 2. 1997. MARCHAND, P. Marshall McLuhan: The Medium and the Messenger. Toronto: Random House. 1989.

MARCHESSAULT, J.; GULDIN, R. Introduction. Flusser Studies, [s.l.], n. 6, maio, 2008. McLUHAN, M. A Galáxia de Gutenberg: a formação do homem tipográfico. São Paulo, Editora da USP, 1972.

MARCHESSAULT, J.; GULDIN, R. Understanding Me: Lectures and Interviews; In: McLUHANcLuhan,, M.;, McLuhan, S., STAINES, D., Eds.; Toronto, ON, Canada: McClelland \& Stewart, 2003.

MARCHESSAULT, J.; GULDIN, R. Essential McLuhan. Eds. E. McLuhan. E.; and F. Zingrone, F. London: Routledge. 2005a.

MARCHESSAULT, J.; GULDIN, R. McLuhan por McLuhan. Rio de Janeiro: Ediouro, 2005b. MARCHESSAULT, J.; GULDIN, R. Os meios de Comunicação como extensões do homem. São Paulo: Cultrix, 1969.

McLUHAN, M..; FIORE, Q.; AGEL, J. The Medium is the Massage: An Inventory of Effects. New York: Random House, 1967

MERSCH, D. Kritik des Medienteleologismus. McLuhan, Flusser und Hegel, In: DE KERCKHOVE, D.; LEEKER, M.; \& SCHMIDT, K., McLuhan neu lesen. Kritische Analysen zu Medien und Kultur im 21. Jahrhundert, [s.l.], Bielefeld (transcript) 2008., S. 196-209

MEULEN, Sjoukje. Between Benjamin and McLuhan: Vilém Flusser's Media Theory. New German Critique. Durham, n. 37, 2010, p. 180-207.

NODARI, A. Um Réquiem para a escrita? Resenha. Revista Sopro, [s.l.], n. 10, v. 10, abr. 2010.

PANDILOVSKI, M. What lies behind modern technology? The approaches of Marshall McLuhan and Vilém Flusser. Glimpse, [s.l.], v. 17, 2016. p.77-85.

SCHAEFER, P. Vilém Flusser's philosophy of new media history. New Media \& Society, v.13, n. 8, 2011. p. 1389-1395. 
STRÖHL, A. Introduction. In: FLUSSER, Vilém. Writings. Org. A. Ströhl (Org.). London: University of Minnesota Press, 2002.

TREMBLAY, G. "From Marshall McLuhan to Harold Innis, or From the Global Village to the World Empire". Canadian Journal of Communication, Toronto, North America, n. 37, dez. 2012.

VON AMELUNXEN, H. Afterword. In: FLUSSER, V. Towards a Philosophy of Photography. London: Raktion Books, 2006. p.86-94.

WEISS, S. L. Human Consciousness and the Construct of Meaning in the Communication Theories of Marshall McLuhan and Vilém Flusser. Flusser Studies, [s.l.], n. 6, maio, 2008.

\title{
Vilém Flusser e Marshall McLuhan and the ages of communication
}

\begin{abstract}
The paper proposes a debate on how Vilém Flusser and Marshall McLuhan discuss the transitions between different communicational ages. Through bibliographic analysis we conclude that they share the centrality of communication to understand society, as well as the non-neutrality of the media. We conclude that Flusser is closer to McLuhan than he admits, but that there are important differences in the way they understand the transitions between communicational ages.
\end{abstract}

\section{Keywords}

Vilém Flusser. Marshall McLuhan. Communication Epistemology. Communication Ages.

Recebido em 30/04/2020

Aceito em 14/05/2020 